\title{
Hello World!: Uma Experiência de Aprendizagem de Computação em Espaço Não-Formal de Educação
}

\author{
João Silvestre dos Santos Franco ${ }^{1}$, Jorge Costa Leite Junior ${ }^{1}$ \\ ${ }^{1}$ Instituto Federal da Bahia (IFBA), Campus Santo Amaro \\ Grupo de Informática Aplicada (GIA) \\ $1^{\text {a }}$ Travessa São José, s/no , Bomfim - Santo Amaro, BA - Brasil \\ \{joao.franco, leitejr\}eifba.edu.br
}

\begin{abstract}
Considering the internship as a research field, this paper presents the experience of supervised internship in Computer Science teaching in a nonformal space with teenagers aged 13 to 15 years, in Santo Amaro - BA. As an extension project, in order to promote a tinkering based learning, the Scratch programming language and online community was adopted as main teaching resource. Other activities were Computer Science Unplugged practices, Code.org courses and an educational robotics workshop. It was concluded that the proper use of Scratch may be an important strategy to encourage creative learning of Computer Science themes and other knowledge areas.
\end{abstract}

Resumo. Trazendo a perspectiva do estágio como campo de pesquisa, este trabalho apresenta experiências do estágio supervisionado em Computação em espaço não-formal, na cidade de Santo Amaro - BA, com adolescentes na faixa etária de 13 a 15 anos. Seguindo o formato de projeto de extensão, para promover uma aprendizagem baseada na exploração criativa, utilizou-se a linguagem de programação visual e comunidade virtual Scratch. Também aconteceram práticas de Computação Desplugada, desafios no Code.org e uma oficina de robótica educacional. Concluiu-se que o uso adequado do Scratch pode ser uma importante estratégia para aprendizagem criativa de temas tanto da Computação quando de outras áreas do conhecimento.

\section{Introdução}

O amplo acesso e a evolução das tecnologias digitais de informação e comunicação (TDIC), evidenciados, sobretudo, pela democratização da internet e presença de smartphones, tablets e dispositivos vestíveis entre as massas, proporcionaram mudanças significativas no âmbito das relações de trabalho, no consumo e produção de bens e serviços e, inevitavelmente, na educação.

Neste cenário de rápidas e constantes transformações, a Computação desempenha um papel essencial na concepção de tais tecnologias; desta forma, a privação ao acesso e domínio dos conhecimentos desta área é também fator inclusão ou exclusão de indivíduos na sociedade contemporânea. Embora, equivocadamente, tende-se a associar estes conhecimentos à satisfação de necessidades meramente mercadológicas para formação de mão de obra, para além disso, os currículos das instituições educacionais precisam acompanhar as transformações para atender às demandas de uma sociedade que requer criatividade na concepção e implementação de soluções em favor de uma vida melhor. 
As mudanças na educação são complexas e transcendem a readequação de espaços físicos e adoção de dispositivos digitais; exigem instituições de ensino acolhedoras, que compreendam as singularidades dos sujeitos e dêem espaço às diferentes formas de aprender. Mais que isso, exigem formar professores que sejam agentes catalisadores destas transformações. Neste processo formativo, o estágio supervisionado curricular é uma fase essencial na formação docente e tem o papel de "possibilitar que os futuros professores compreendam a complexidade das práticas institucionais e das ações aí praticadas por seus profissionais como alternativa no preparo para sua inserção profissional" [Pimenta e Lima 2012, p. 43].

Nesta perspectiva, este trabalho apresenta atividades de um projeto de extensão, intitulado "Hello World!", ocorrido no âmbito do estágio supervisionado em Computação, do curso de licenciatura em Computação do Instituto Federal de Educação, Ciência e Tecnologia da Bahia (IFBA), campus Santo Amaro. Ao superar a noção de estágio como apenas a "parte prática do curso", este trabalho traz o estágio como campo de pesquisa, como caminho para superação da dicotomia teoria-prática; para Pimenta e Lima (2012, p. 46), "a pesquisa no estágio é uma estratégia, um método, uma possibilidade de formação do estagiário como futuro professor".

Desenvolvido como atividade de extensão na etapa do estágio supervisionado curricular em espaço não-formal, o objetivo deste projeto foi promover estratégias para estimular a aprendizagem criativa, o desenvolvimento de lógica de programação e conceitos básicos da Computação entre estudantes da educação básica $\left(9^{\circ}\right.$ ano do ensino fundamental e $1^{\circ}$ ano do ensino médio), atento aos referenciais curriculares para a educação básica apresentados pela Sociedade Brasileira de Computação (SBC) [Raabe et al. 2017]. Ao longo do projeto, aconteceram reuniões com atividades apoiadas pelo Scratch, introduzidas por atividades de Computação Desplugada.

O trabalho foi organizado da seguinte maneira: na seção 2, apresenta-se o referencial teórico que embasou a prática, centrada na exploração e aprendizagem criativa, intrinsecamente ligadas ao Scratch; já na seção 3, mostra-se o percurso metodológico para o desenvolvimento das práticas; na seção 4, por conseguinte, são trazidas as atividades desenvolvidas; ao final, na seção 5, são tecidas as considerações finais.

\section{Referencial teórico}

Enquanto prática social, a educação está inserida e integrada a um sistema educacional de forma tão complexa, que não é possível tratá-la "como fenômeno universal e abstrato", e sim apenas a partir do contexto da sociedade e do período histórico específicos de que se trata, como observam Pimenta e Lima (2012, p. 54), bem como sujeitos envolvidos.

No âmbito da cultura digital, para Valente, Almeida e Geraldini (2017), o currículo e as metodologias precisam focar em uma aprendizagem ativa, de modo que o estudante seja o protagonista do processo educativo. Diante disso, Kenski (2003, p. 9) ressalta que as aprendizagens "se apresentam como construções criativas, fluidas, mutáveis, que contribuem para que as pessoas e a sociedade possam vivenciar pensamentos, comportamentos e ações criativas e inovadoras".

Tendo isto em vista, o estímulo à "colaboração, o empreendedorismo e a criatividade" é uma característica das sociedades dinâmicas e uma "educação de qualidade, além 
de ensinar a pensar, pode ensinar a viver", conforme Moran (2017, pp. 63-65). Devese acrescentar, como aponta Kenski (2003, p. 3), que "toda aprendizagem, em todos os tempos é mediada pelas tecnologias disponíveis", pois a tecnologia e o humano são indissociáveis. No contexto da cultura digital, com a intensa relação entre conhecimento e tecnologias, é fundamental "ressignificar o próprio conceito de educação e seus modos de fazer" [Valente, Almeida e Geraldini 2017, p. 458].

Resnick e Rosenbaum (2013, p. 4) enfatizam que "brincar é uma forma de interagir com o mundo, um processo de testar limites e novas possibilidades"; o Scratch favorece esse processo ao permitir a abordagem de tinkering - exploração criativa - e propiciar uma aprendizagem criativa, bem representada pela espiral Imaginar - Criar Brincar - Compartilhar - Refletir, como traz Resnick (2014, p. 2), num processo em que os estudantes

\begin{abstract}
imaginam o que querem fazer, criam um projeto com base em suas ideias, brincam com suas criações, compartilham suas ideias e criações com outras pessoas, refletem sobre suas experiências - e tudo isso os leva a imaginar novas ideias e projetos. Enquanto os alunos passam por esse processo, cada vez mais eles aprendem a desenvolver suas próprias ideias, testá-las, testar limites, experimentar alternativas, ouvir as opiniões dos outros e criar novas ideias com base em suas experiências. Nesse processo, eles se desenvolvem como pensadores criativos. [grifos do autor]
\end{abstract}

Quando ocorre ativamente, segundo Resnick (2020), o processo de desenvolvimento, construção e criação proporciona as experiências de aprendizagem mais valiosas. Entretanto, a maioria das iniciativas voltadas para aprendizagem na área de programação desconsideram a importância da expressão criativa do aprendente [Resnick e Siegel 2015]; nesse sentido, embora forneça subsídios para a aquisição de conhecimento de conceitos básicos, a ênfase acrítica de tais conceitos traz prejuízos à construção de saberes futuros, devido à abstração não significativa do conhecimento.

Para Resnick e Siegel (2015), com o Scratch, as possibilidades de aprendizagem se expandem, porque, além de aprender aspectos relacionados aos conceitos de codificação, os estudantes também têm chances para expressar-se livremente, o que contribui para o desenvolvimento da criatividade. Diante desta perspectiva, o projeto desenvolvido no estágio supervisionado foi baseado na abordagem de tinkering com a linguagem Scratch.

Como recurso digital, o Scratch destaca-se pela abordagem simples, que possibilita aplicá-lo do ensino básico ao nível superior; como fruto de um projeto criado pelo grupo Lifelong Kindergarten, do MIT Media Lab, consiste em blocos de instruções que permitem às crianças testar diferentes sequências e combinações, de maneira muito semelhante ao que acontece com LEGO [Resnick e Rosenbaum 2013]. Além disso, ao permitir a junção dessas sequências e pequenos pedaços de código a unidades maiores, o Scratch estimula uma aprendizagem prática numa abordagem de baixo para cima [Maloney et al. 2010].

A possibilidade de compor projetos multimídia com textos, sons e imagens, cujas ações são controladas por meio de "scripts de programação e fantasias para cada ator", como destacam Resnick e Rosenbaum (2013, p. 9), abre espaço para o tinkering por meio das sucessivas e iterativas transformações nos códigos dos atores e cenários. Deste modo, o resultado pode sempre ser revisto e adaptado pelo(s) usuário(s), com a possibilidade de 
observar, extrair e adaptar, de outros usuários da comunidade online, "novas técnicas de programação que podem ser usadas em seus próprios projetos" [Resnick 2020, p. 95].

Na comunidade online do Scratch, essa possibilidade surge ao remixar um projeto compartilhado; no remix, é possível modificar o projeto inserindo (ou extraindo) elementos de mídia ou scripts dos respectivos atores. De acordo com Resnick (2020, p. 95), o "scratching", que pode ser traduzido para o português como "arranhar", deu origem ao nome do Scratch e consiste na "técnica utilizada por DJs de hip-hop para remixar trechos de músicas de maneiras criativas". Assim, o remix está diretamente associada "aos valores básicos de abertura e de criatividade" e, por esta razão, qualquer projeto criado no Scratch pode ser visto/remixado desde que o autor original receba os devidos créditos.

\section{Percurso metodológico}

Do ponto de vista metodológico, este trabalho consiste em um estudo de caso sobre aprendizagem criativa na educação básica em espaço não-formal, cujos dados foram coletados num período que compreende os meses de março a julho de 2019, a partir de diários de bordo elaborados pelos professores/estagiários estudantes do curso de Licenciatura em Computação, do IFBA - Campus Santo Amaro, responsáveis pela concepção e aplicação do projeto, bem como os instrumentos de avaliação do aprendizado.

$\mathrm{O}$ projeto atendeu estudantes do $9^{\circ}$ ano do ensino fundamental e $1^{\circ}$ ano do ensino médio regular de instituições públicas e privadas da cidade de Santo Amaro, no Recôncavo da Bahia. Foram realizadas visitas à escola municipal mais próxima do campus do IFBA, onde os encontros foram realizados, além de fichas de interesse, disponibilizadas em meio online; metade das vagas foram disponibilizadas para estudantes com parentesco com funcionários terceirizados ou estudantes de cursos noturnos nas modalidades educação de jovens e adultos (EJA) e subsequente.

Com duração média de 3 horas diárias e intervalos de 20 minutos, todos os encontros seguiram a dinâmica de um momento inicial, onde foram aplicadas atividades de Computação Desplugada, em que fundamentos da Computação são abordados sem computador [Bell et al. 2011], para introduzir o tema das atividades do dia, seguidas de desafios que buscavam estimular os participantes a pensar e discutir sobre um determinado problema relacionado ao tema.

Assim, no desenvolvimento do projeto, foram propostas atividades voltadas para colaboração, cooperação e diálogo, como debates acerca de temas específicos e discussões com demonstrações na resolução de problemas, além do estímulo ao pensamento computacional a partir da Computação Desplugada, colaboração e autoria em atividades realizadas no Code.org e, sobretudo, no Scratch.

Sob o prisma da aprendizagem criativa, nas atividades desenvolvidas no projeto, o "imaginar" refere-se à concepção inicial do produto a ser construído no âmbito das atividades, isto é, o que o estudante pensa em fazer: um jogo? Uma história interativa animada? Como ele imagina aquele tema/tópico sendo abordado? Já na etapa de "criar", quando o estudante "põe a mão na massa", começa a montar os blocos, sob orientação do professor para começar a experimentar as possibilidades com o recurso; o foco é aprimorado a partindo dessas explorações iniciais, num processo "de baixo e cima que torna o tinkering um processo valioso" [Resnick e Rosenbaum 2013, p. 6]. 
A respeito do "brincar" e "compartilhar", ocorreram rodas de compartilhamento dos projetos com posterior discussão do que foi construído, além de utilizar a comunidade online do Scratch. Os estudantes literalmente exploraram e avaliaram os próprios trabalhos e dos demais colegas; com as demonstrações dos trabalhos com diálogos entre o grupo, foi construído um ambiente que favoreceu uma aprendizagem colaborativa, com pequenas intervenções nos projetos para inserção de novas funcionalidades.

$\mathrm{Na}$ última etapa, os participantes foram convidados a "refletir" sobre os projetos criados, repensando também a lógica de programação utilizada pelos colegas, a partir de provocações como: por que você implementou isto dessa forma? Por que utilizou um bloco do tipo "if (condição)...else" em vez de "if (condição)"? Por que usar um bloco "wait until" em vez de outra estrutura condicional? Como você criou esta animação nos atores e como poderia fazê-la de forma diferente, mais desafiadora, instigante ou real? Provocados, apresentaram novas ideias e imaginaram novas possibilidades.

\section{Desenvolvimento das atividades e discussão}

As semanas iniciais foram dedicadas a estabelecer vínculos com os estudantes, que demonstravam muita timidez nos primeiros encontros. Como a intenção, desde o princípio, era permitir que expressassem criatividade principalmente pelas construções no Scratch, foram elaboradas estratégias de aproximação para conhecer os participantes, de forma que fosse possível dialogar sobre as dificuldades encontradas ante à lógica de programação, que era novidade para o grupo. Houve uma etapa de apresentação verbal seguida de atividades escritas, em que buscou-se detectar o que os estudantes já sabiam sobre Computação, Informática e programação, e o que esperavam aprender no projeto.

Inicialmente, adotou-se atividades no Code.org como lição de casa; em todo encontro, antes de ir para a área externa ao laboratório de informática para as atividades de Computação Desplugada, etapa inicial das atividades, aconteceram discussões sobre a evolução e sobre as soluções e dificuldades encontradas em cada desafio. Após a terceira semana, observada a frequência dos participantes às reuniões do projeto, avaliou-se que o uso das atividades do Code.org em paralelo e como complemento às atividades no Scratch não estava gerando retorno positivo na aprendizagem individual de parte dos estudantes com presença frequente.

Foram indicados os cursos Minecraft Adventurer, Code with Anna and Elsa, Flappy Code, Star Wars: Building a Galaxy With Code (Blockly) e, por fim, Dance Party (2018), baseadas em puzzles de lógica, em que o usuário programa o comportamento dos personagens usando blocos, como observam Resnick e Rosenbaum (2013); nesse caso, porém, a aprendizagem não é baseada em projetos e, para os autores, ainda que aprendam conceitos computacionais importantes, não desenvolvem a capacidade de livre expressão.

Além disso, no projeto, como essas lições do Code.org são divididas em níveis que são avançados conforme o usuário programa uma solução, percebeu-se que havia uma distância significativa entre os estudantes nos níveis de cada atividade. Embora essa distância seja natural - afinal, são sujeitos com diferentes origens, características, modos e tempos de aprendizagem distintos -, quando os participantes retornavam às discussões na sala, os projetos em que estavam envolvidos eram diferentes, com blocos de comando de tipos diferentes, considerando as lições mencionadas acima. Somado às dificuldades em resolver os desafios, alguns participantes relataram dificuldades de acesso à plata- 
forma em casa. Assim, considerando as limitações de tempo nas reuniões e no acesso dos estudantes, optou-se em utilizar apenas o Scratch nas atividades orientadas, colaborativas e individuais.

Para alcançar os objetivos do projeto, diversas atividades foram propostas e aplicadas no decorrer dos encontros ao longo do estágio supervisionado. Dentre estas, as subseções abaixo trazem uma síntese das atividades realizadas de forma sistematizada.

\subsection{Atividades desplugadas}

As atividades de Computação Desplugada quase sempre ocorreram ao ar livre, aproveitando as áreas externas do campus num movimento de ocupação dos espaços da instituição pelos estudantes, oriundos de diferentes escolas e regiões da cidade. Esses momentos contribuíram fortemente para a integração dos participantes, ao mesmo tempo em que ajudou a prepará-los para as tarefas no Scratch e para a oficina de Robótica Educacional. Algumas das atividades, como "Colorindo com números", foram baseadas em Bell et al (2011), como ilustra a figura 1, que traz também atividades ao ar livre.
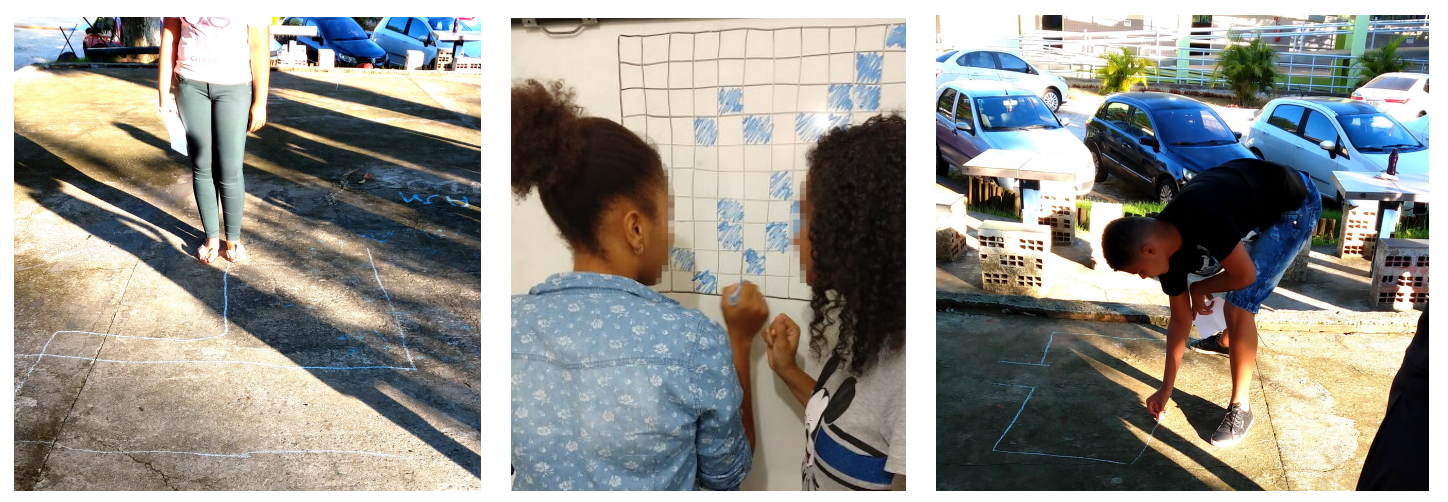

Figura 1. Atividades desplugadas em sala de aula e nas área externa do campus

Em uma das atividades na área externa, os participantes foram divididos em equipes; cada equipe foi convidada a montar mapas, que seriam desenhados com giz no chão. Como uma "caça ao tesouro", com alguns comandos simples como "andar" ou "virar à esquerda", estabelecidos pelas equipes oponentes, os outros grupos tinham que elaborar e testar estratégias de solução. Um dos grupos, por exemplo, concluiu que seria inviável realizar mapas que envolviam circunferências sem criar comandos como "girar $360^{\circ}$ ". Essas atividades foram importantes por demonstrar, de forma concreta, algumas noções que os estudantes precisariam para avançar na construção dos projetos no Scratch, como noções básicas de coordenadas cartesianas e ângulos.

\subsection{Oficina de robótica educacional}

Para satisfazer a curiosidade dos estudantes com uma das extensões do Scratch, com a participação do grupo de robótica educacional do Programa Institucional de Bolsas de Iniciação à Docência (PIBID), foi ofertada uma oficina de robótica usando o LEGO Mindstorms. Durante a oficina, os participantes tiveram uma rápida introdução à robótica educacional e puderam visualizar e brincar com motores, sensores, engrenagens e rodas, disponíveis no kit em uso pelo grupo do PIBID. 

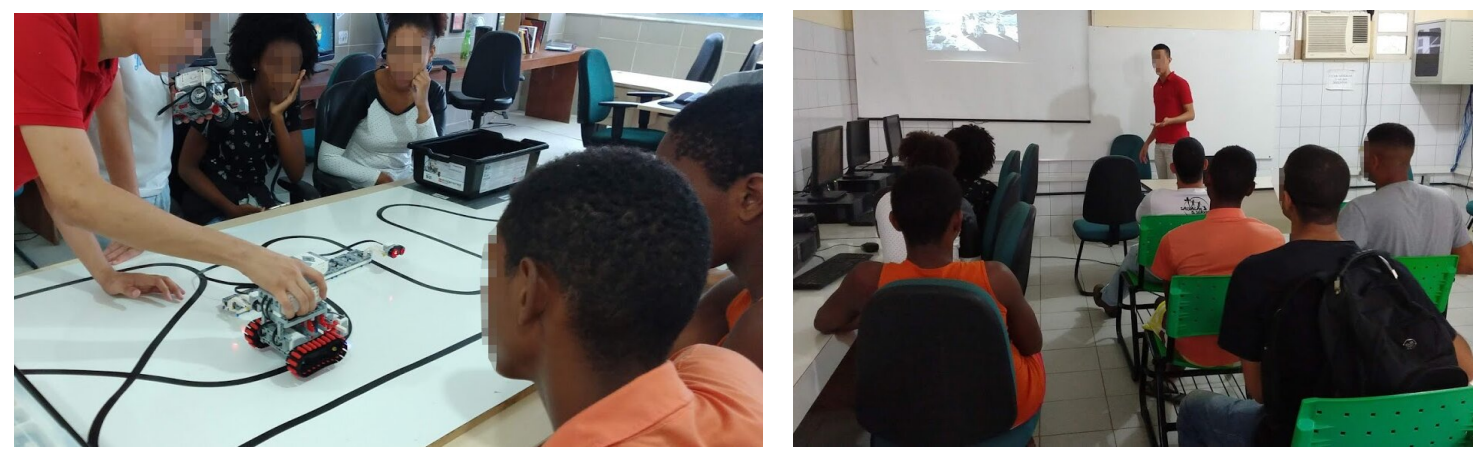

Figura 2. Imagens da oficina de robótica educacional com LEGO Mindstorms

Foram exibidos vídeos de competições de robôs e, nas conversas, houve um confrontamento com experiências anteriores dos estudantes, inclusive em filmes, vídeos e programas de TV e internet. Embora o tempo reduzido da oficina tenha sido insuficiente para avançar nos projetos - afinal, além desta oficina não estar prevista no planejamento original, os kits de robótica tinham uso definido pelo grupo do PIBID - os estudantes puderam imaginar e testar possibilidades com os recursos.

Como elemento motivador, a resposta foi positiva; depois da oficina, notou-se que os participantes se mostraram mais envolvidos; por iniciativa própria, alguns estudantes se propuseram a montar uma apresentação sobre robótica educacional com o que foi visto na oficina, além de pesquisas independentes.

\subsection{Criação de jogos, histórias e animações interativas com o Scratch}

\subsubsection{Temática direcionada: a semana de abolição da escravatura no Brasil}

Na semana da abolição da escravatura no Brasil, foram realizadas rodas de discussão sobre o processo de abolição, seguindo a linha das temáticas em evidência na educação formal dos estudantes, naquele período. Em Santo Amaro, o dia 13 de maio tem importância ainda maior em razão do Bembé do Mercado, movimento de característico da cultura santo-amarense na afirmação de descendentes de africanos escravizados. Neste sentido, foi proposto que os estudantes elaborassem projetos sobre o tema no Scratch, partindo de pesquisas na rede e das discussões desenvolvidas.

Embora as discussões tenham sido proveitosas para o desenvolvimento do tema, os estudantes apresentaram dificuldades na implementação das ideias no Scratch; para atenuá-las, optou-se por dar sequência ao projeto com outras atividades, mais voltadas para a exploração do Scratch. Entre as atividades desplugadas e discussões em sala, foram utilizados os tutoriais e os cards disponibilizados na página do Scratch. Assim, os estudantes tiveram maior liberdade criativa sobre os temas, de modo que, no processo criativo proposto nas atividades, puderam reavaliar "continuamente suas metas, explorando novos caminhos e imaginando novas possibilidades" [Resnick e Rosenbaum 2013, p. 2].

Por outro lado, mesmo com uma resposta positiva a essas atividades no que se refere à fluência no Scratch, avaliou-se que não dar continuidade às atividades iniciadas sobre o tema mencionado acima foi uma falha do projeto. Como ressalta Resnick (2020, p. 44), tanto na aprendizagem de programação quanto da escrita, é fundamental aprender a comunicar-se e expressar-se e, portanto, não basta dominar "ortografia, gramática e 
pontuação". Deste modo, ao limitar o tempo disponível para a criação e experimentação do Scratch, limitou-se, também, o desenvolvimento da expressão criativa dos estudantes.

Assim, o tema da abolição da escravatura poderia (e deveria) ter sido explorado com provocações sobre o tema, insistindo nas discussões como caminho para a incrementação dos projetos iniciados, pensando a abordagem baseada em tinkering como "um processo contínuo de revisão e adaptação" [Resnick e Rosenbaum 2013, p. 10]. Um caminho alternativo para isso seria o uso de remix de projetos na comunidade online, como forma de contribuir não apenas para o desenvolvimento da fluência no Scratch, mas também da criatividade dos estudantes atrelada ao domínio deste recurso.

\subsubsection{Temática livre: projetos finais e conclusão das atividades}

Na etapa final do projeto, os estudantes foram convidados a elaborar jogos com tema livre, a partir dos conhecimentos desenvolvidos nas etapas anteriores. Para isto, foi proposto o uso das extensões Text to Speech, Pen, Translate e Video Sensing, que não haviam sido exploradas inicialmente. Em duplas, eles e elas criaram jogos explorando recursos dessas extensões, com as premissas imaginadas, criadas e melhoradas dentro da perspectiva da espiral criativa apresentada neste texto.
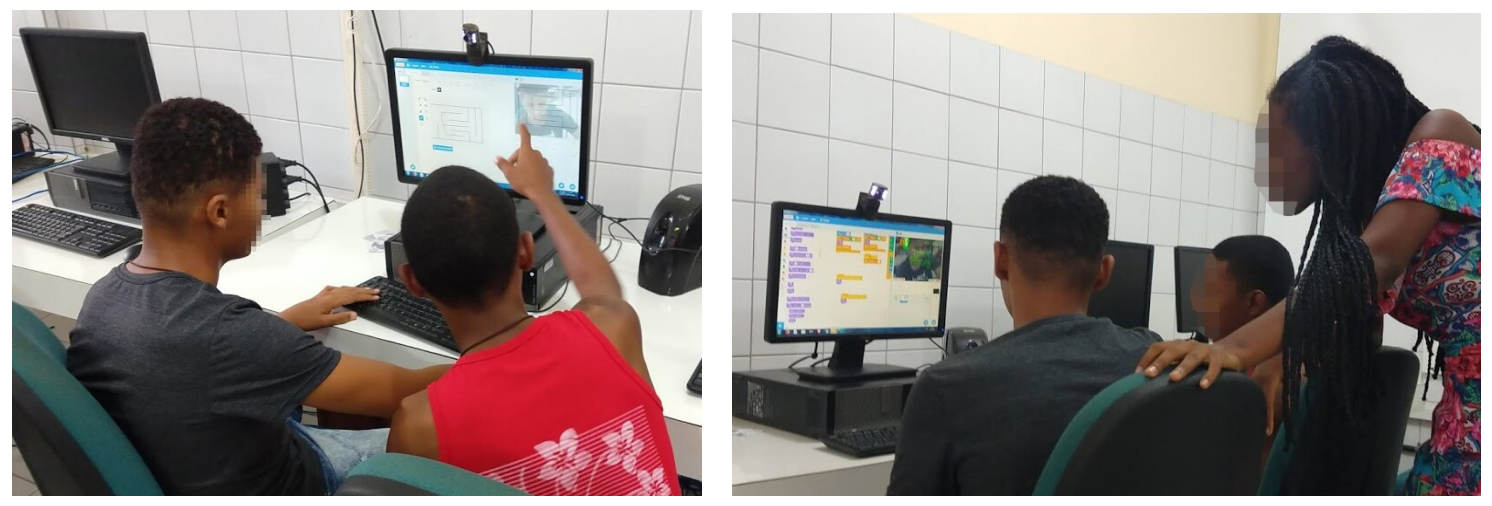

Figura 3. Participantes testam e compartilham o que aprenderam sobre a extensão do Video Sensing do Scratch

Acima, a figura 3 ilustra o trabalho de uma das duplas: inicialmente, um labirinto controlado por vídeo, que, ao final, foi modificado e gerou uma espécie de "caça-moedas", num processo de negociação que remete totalmente ao processo de tinkering: no início da atividade, não havia uma noção clara do que queriam fazer, uma meta; no decorrer do processo, brincando com a extensão de Video Sensing, a dupla criou um projeto que foi incrementado e renegociado "com base nas suas interações com os materiais e com as pessoas com quem estão trabalhando" [Resnick e Rosenbaum 2013, p. 3].

As experimentações evidenciam o tinkering na aprendizagem dos conceitos de programação e outros temas, como foi o caso da abolição da escravatura. A liberdade de escolha dos temas tratados nos projetos com o Scratch não é algo fortuito; na prática, os resultados dos experimentos dos participantes com as extensões permitiram que essas explorações preliminares pudessem evoluir para projetos com intenções bem definidas, num sentido de baixo para cima, cujo arranjo é o que faz a exploração criativa ser um processo tão poderoso [Resnick e Rosenbaum 2013]. 

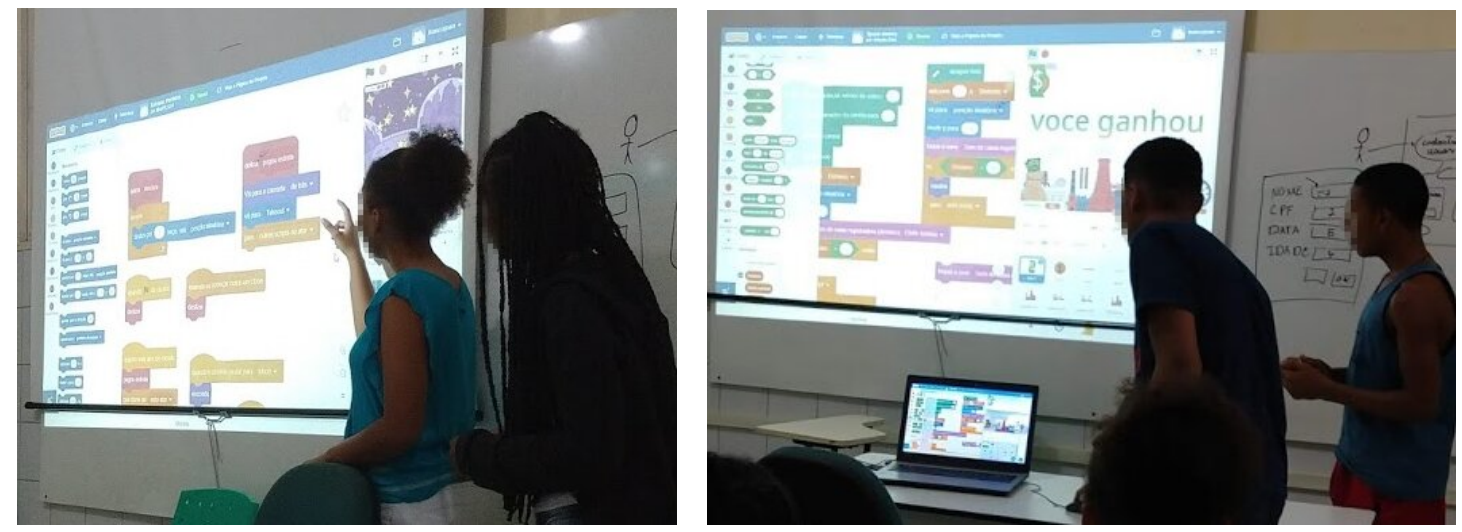

Figura 4. Participantes testam e compartilham o que aprenderam sobre a extensão do Video Sensing do Scratch

Inicialmente, a falta de microfones e webcams suficientes para todos foi encarada como um problema. Para contorná-lo, os participantes foram encorajados a montar um esquema de compartilhamento dos recursos disponíveis. Após a moção inicial na disputa pelos materiais, ocorreu um movimento de cooperação entre as duplas, que, além de compartilhar o recurso, conforme avançavam na exploração das extensões passaram a compartilhar também o que já haviam imaginado e construído com os demais, para que pudessem incorporá-las em seus projetos.

Com os projetos finais, percebeu-se uma evolução na aprendizagem de conceitos de Computação/Informática, sobretudo, na fluência em programação. Além de desenvolver os projetos, as duplas compartilharam com todo o grupo as soluções implementadas, em apresentações que exigiram dos participantes capacidade de "improvisar, adaptar e iterar, sem depender de planos velhos quando surgem situações novas" [Resnick e Rosenbaum 2013, p. 5], isto é, moldar os projetos dentro das circunstâncias apontadas nas intervenções dos demais colegas (ou defender as próprias ideias), algo essencial "em um mundo em constante mudança".

\section{Considerações finais}

O contexto não formal do projeto possibilitou a superação de entraves impostos pelo sistema educacional, como o caráter disciplinar, que tende a tornar o conhecimento fragmentado, além da idade, tempo e espaço; para Resnick (2020, p. 166), estas são barreiras dificultam o atendimento às demandas de uma sociedade criativa e, portanto, precisam ser rompidas para possibilitar aos estudantes "a oportunidade de trabalhar em projetos que integrem ciências, arte, engenharia e design".

Por meio do acervo de mídias do Scratch, foi possível criar projetos com livre inspiração em temas de várias áreas do conhecimento, o que reforça a possibilidade de uso do Scratch também na educação formal por docentes de História, Geografia e Matemática, que podem trabalhar temas de suas respectivas áreas a partir de um mesmo projeto piloto. Soma-se a isso a possibilidade de importar mídias externas, desenhar e gravar sons para uma abordagem baseada em tinkering.

Ademais, os testes dos blocos de código com resultado em tempo real do Scratch possibilita um processo "inerentemente iterativo", como delineiam Resnick e Rosenbaum 
(2013) — tinkering por essência —, o que se permite uma aprendizagem por exploração, experimentação e revisão. Nesse contexto, criativamente, os estudantes aprenderam conceitos computacionais como representação de imagens, variáveis, estruturas condicionais e de repetição, além de operações matemáticas e de lógica booleana.

Como trabalhos futuros, pretende-se mapear atividades desplugadas e criar propostas para aprendizagem criativa utilizando o Scratch, a partir de temas de outras áreas do conhecimento, organizando sequências didáticas para práticas multi e interdisciplinares da educação básica. Neste sentido, por fim, destaca-se o papel do licenciado em Computação na educação básica na concepção de atividades nos moldes do que foi apresentado neste artigo, na tentativa de superar a fragmentação do conhecimento que, de modo geral, estabelece-se nos sistemas educacionais, para propor uma aprendizagem mais ativa e criativa, que atenda às demandas da sociedade contemporânea.

\section{Referências}

Bell, T., Witten, I. H., and Fellows, M. (2011). Ensinando Ciência da Computação sem o uso do computador. Computer Science Unplugged ORG.

Kenski, V. M. (2003). Aprendizagem mediada pela tecnologia. Revista Diálogo Educacional, 4(10):47-56.

Maloney, J., Resnick, M., Rusk, N., Silverman, B., and Eastmond, E. (2010). The scratch programming language and environment. ACM Transactions on Computing Education (TOCE), 10(4):1-15.

Moran, J. (2017). Como transformar nossas escolas: novas formas de ensinar a alunos sempre conectados. In CARVALHO, M., editor, Educação 3.0: Novas perspectivas para o Ensino, pages 63-87. Sinepe/RS/Unisinos, Porto Alegre.

Pimenta, S. G. and Lima, M. S. L. (2012). Estágio e docência. Cortez Editora, São Paulo, 7 th edition.

Raabe, A. L. A., Zorzo, A. F., Frango, I., Ribeiro, L., Granville, L. Z., Salgado, L., da Cruz, M. J. K., Bigolin, N., Cavalheiro, S. A. C., and Fortes, S. (2017). Referenciais de Formação em Computação: Educação Básica. Sociedade Brasileira de Computação (SBC).

Resnick, M. (2014). Give P's a chance: Projects, peers, passion, play. pages 13-20, Vienna. Constructionism and creativity: Proceedings of the third international constructionism conference, Austrian Computer Society.

Resnick, M. (2020). Jardim de infância para a vida toda: por uma aprendizagem criativa, mão na massa e relevante para todos [recurso eletrônico]. Penso, Porto Alegre.

Resnick, M. and Rosenbaum, E. (2013). Designing for tinkerability. In Honey, M. and Kanter, D., editors, Design, Make, Play: Growing the Next Generation of STEM Innovators, pages 163-181. Routledge.

Resnick, M. and Siegel, D. (2015). A different approach to coding. International Journal of People-Oriented Programming, 4(1):1-4.

Valente, J. A., Almeida, M. E. B., and Geraldini, A. F. S. (2017). Metodologias ativas: das concepções às práticas em distintos níveis de ensino. Revista Diálogo Educacional, 17(52):455-478. 